\title{
DIFICULDADES EXPERIENCIADAS PELOS AGENTES COMUNITÁRIOS DE SAÚDE NA REALIZAÇÃO DA EDUCAÇÃO EM SAÚDE
}

Jessica Mayara Almeida Silva1, Bruno Dias Batista, Andressa Pereira do Carmo, Marilia Moreira Torres Gadelha, Mayara Evangelista de Andrade, Marcelo Costa Fernandes

Objetivo: Analisar as dificuldades experienciadas pelos Agentes Comunitários de Saúde no seu cotidiano na realização da educação em saúde na Atenção Básica. Metodologia: Pesquisa descritiva, de cunho qualitativo, sustentada nos marcos conceituais da análise de discurso de Michel Pêcheux. Resultados: Identificou-se fatores que geravam dificuldades no cotidiano das práticas de educação em saúde e por consequência restrição nas ações realizadas pelos agentes. Discussões: As principais dificuldades foram: resistência do público em participar das ações; influências do modelo biomédico; falta de apoio da gestão e necessidade de utilização da barganha como método de incentivo para que a população participe das atividades de educação em saúde. Conclusão: Torna-se importante ressaltar a construção do cuidado em busca de superar os empecilhos da rotina de trabalho em relação à educação em saúde, visto ser a mesma uma possibilidade de empoderamento social.

Descritores: Estratégia Saúde da Família; Agentes Comunitários de Saúde; Educação em Saúde.

\section{DIFFICULTIES EXPERIENCED BY COMMUNITY HEALTH AGENTS IN THE CONDUCT OF HEALTH EDUCATION}

Objective: To analyze the difficulties experienced by the Community Health Agents in their daily life in the realization of health education in Primary Care. Methodology: Descriptive research, of a qualitative nature, based on the conceptual frameworks of Michel Pêcheux's discourse analysis. Results: We identified factors that generated difficulties in the daily life of health education practices and, consequently, a restriction on the actions performed by the agents. Discussion: The main difficulties were: public resistance to participate in actions; influences of the biomedical model; lack of management support and the need to use bargaining as a method of encouraging the population to participate in health education activities. Conclusion: It is important to emphasize the construction of care in order to overcome the obstacles of the work routine in relation to health education, since it is a possibility of social empowerment.

Descriptors: Family Health Strategy; Community Health Worker; Health Education.

\section{DIFICULTADES EXPERIENCIAS POR LOS AGENTES COMUNITARIOS DE SALUD EN LA REALIZACIÓN DE LA EDUCACIÓN EN \\ SALUD}

Objetivo: Analizar las dificultades experimentadas por los Agentes Comunitarios de Salud en su cotidiano en la realización de la educación en salud en la Atención Básica. Metodología: Investigación descriptiva, de cuño cualitativo, sostenida en los marcos conceptuales del análisis de discurso de Michel Pêcheux. Resultados: Se identificaron factores que generaban dificultades en el cotidiano de las prácticas de educación en salud y por consecuencia restricción en las acciones realizadas por los agentes. Discusiones: Las principales dificultades fueron: resistencia del público en participar de las acciones; influencias del modelo biomédico; falta de apoyo de la gestión y necesidad de utilización de la negociación como método de incentivo para que la población participe en las actividades de educación en salud. Conclusión: Es importante resaltar la construcción del cuidado en busca de superar los escollos de la rutina de trabajo en relación a la educación en salud, ya que es la misma una posibilidad de empoderamiento social.

Descriptores:Estrategia de Salud Familiar; Agentes Comunitarios de Salud; Educación en Salud. 


\section{INTRODUÇÃO}

A Atenção Básica $(A B)$, espaço de produção de cuidado à saúde, é marcada pela presença do Agente Comunitário de Saúde (ACS), que ocupa lugar essencial na equipe da Estratégia Saúde da Família (ESF). Este trabalhador da saúde ao desenvolver suas práticas cotidianas, em especial as ações educativas, pode influenciar diretamente no aspecto de qualidade de vida da comunidade sob sua responsabilidade.

O ACS atua como facilitador da comunicação entre os profissionais da ESF e a população do território de atuação, o que fomenta a aproximação entre esses atores e, consequentemente, a criação de elos entre estes. Essa atribuição faz com que o ACS seja percebido como trabalhador de referência pela comunidade, o que contribui também para a consolidação de vínculo de confiança com as famílias atendidas e papel de protagonista na prática da educação em saúde.

Mesmo percebendo a imprescindibilidade do ato educativo a ser realizado pelo ACS para as transformações sociais, por vezes tal prática acaba por não ser desenvolvida em sua rotina de trabalho, principalmente devido ao não reconhecimento da população acerca do papel desse trabalhador na realização de ações de cuidado na $A B$ com foco na educação em saúde, o que gera sentimentos de frustação e desmotivação. Destaca-se também a falta de incentivo para a realização das suas ações, assim como de capacitações que deveriam ocorrer por parte da gestão, o que tornaria o ACS mais qualificado em desenvolver em seu cotidiano de trabalho a educação em saúde de forma mais efetiva ${ }^{(1.2)}$.

Logo, a partir das discussões realizadas anteriormente, delimitou-se a seguinte questão norteadora desta investigação: Quais as dificuldades experienciadas pelos ACS na realização da educação em saúde?

Acredita-se que a compreensão de tais dificuldades pode gerar espaços de discussões, em especial no próprio cenário da $A B$, tendo como finalidade a realização do planejamento estratégico, no qual não só os membros da equipe da ESF possam estar envolvidos, mas também a gestão local, com a finalidade de juntos apresentarem melhores condições de trabalho ao ACS na prática da educação em saúde.

Com vista a contribuir com o que foi exposto, o presente estudo teve o objetivo de analisar as dificuldades experienciadas pelos Agente Comunitário de Saúde no seu cotidiano na realização da educação em saúde na Atenção Básica.

\section{METODOLOGIA}

\section{Tipo de estudo}

Pesquisa descritiva, de cunho qualitativo, sustentada nos marcos conceituais da análise de discurso de Michel Pêcheux.

\section{Participantes da pesquisa}

O estudo foi realizado com 16 ACS. Por se tratar da análise de discurso, não houve preocupação com o quantitativo, mas com a profundidade dos discursos. Adotou-se como critério de inclusão para participação na pesquisa: atuar há pelo menos um ano como ACS no município. Como critério de exclusão: estarem ausentes do trabalho por estarem de férias ou em licença de qualquer natureza.

\section{Local do estudo}

A referente pesquisa foi realizada nas Unidades Básicas de Saúde (UBS) do Município de Cajazeiras, no estado Paraiba, a qual faz parte da 4a Macrorregião de Saúde e 9a Gerência Regional de Saúde do estado.

\section{Coleta dos dados}

$\mathrm{Na}$ coleta de dados utilizou-se a entrevista semiestruturada como técnica de coleta de dados. As entrevistas ocorreram no período de dezembro de 2016, na própria UBS, a qual o ACS estava vinculado. Estes foram identificados no estudo pelas letras ACS seguido da numeração conforme a sequência da entrevista.

\section{Procedimentos de análise dos dados}

As informações deste estudo foram analisadas por meio da Análise de Discurso, que oferece informações metodológicas consideráveis para examinar elementos de investigações de interesse de estudos da área da saúde, pois ela se atenta para o "homem falando", visto que trata do discurso como algo em movimento, em que a linguagem é a mediação necessária entre o homem, a realidade natural e social a partir de situações em que se produz o dizer. Não procura interpretar tudo, mas permitir relacionar-se com a linguagem de forma menos explícita( ${ }^{(3)}$.

Assim, Análise de Discurso configura-se como método utilizado para interpretar os vestígios e pistas deixados pelos sujeitos ao longo do corpus. Nesta investigação foram seguidas três etapas descritas a seguir: passagem da superficie linguística para o objeto discursivo; passagem do objeto discursivo para o processo discursivo e passagem do processo discursivo para a formação ideológica ${ }^{(3)}$.

\section{Procedimentos éticos}

Este estudo respeitou a condição humana e seguiu as recomendações da Resolução no 466/2012 do Conselho Nacional de Saúde, acatando todos os requisitos de autonomia, não-maleficência, justiça e equidade, dentre as outras exigências explícitas ${ }^{(4)}$. O qual apenas teve início após a aprovação do projeto pelo Comitê de Ética em Pesquisa (CEP) da Universidade Federal de Campina Grande, campus, Cajazeiras, sob o 
número 1.829.066.

\section{RESULTADOS}

Os enunciados presentes nesta investigação estão relacionados diretamente às formações discursivas, que permite ao ACS elaborar os seus discursos e proferir sob um determinado contexto social, histórico e cultural.

Portanto, neste estudo as formações discursivas apontam de maneira parafrástica empecilhos experenciados pelos ACS no seu cotidiano que dificulta a realização da educação em saúde, sendo uma delas a resistência do público em participar. Tal situação é justificada pelo ACS pelo pouco interesse que a comunidade demostra e a falta de tempo como será exposto a seguir:

"O que dificulta muito é o pouco interesse da comunidade, apesar da gente é [...] falar nos eventos que vai promover [...] mas eles não aparecem, não vem [...]" (ACS 02).

"O que mais dificulta é a falta do compromisso da comunidade para participar das atividades, a gente convida aí no momento eles dizem que vem, mas no dia não vem [...]" (ACS 04).

"É a dificuldade pela comunidade, de você conseguir reunir [...] você não consegue ter muita participação [...]" (ACSO6).

Nos discursos dos participantes outra paráfrase que emerge é a falta de apoio da gestão, que acaba por dificultar a ação educativa, como apresentado em seguida:

"Para realizar essas atividades educativas, [...] a gente tem que ter mais apoio da administração, assim para a gente ter mais palestra mais condição de trabalhar com a comunidade" (ACS 02).

"Penso [...] sei das dificuldades que ela passa (a gestão), mas ela chegando com apoio, com certeza conseguiríamos realizar mais educação em saúde" (ACS 03).

"A gente não tem suporte por parte do gestor, por parte da secretaria de saúde mesmo, nós não temos nenhum suporte pra fazer [...] nenhum incentivo [...]. A secretaria de saúde não ajuda a gente, não dá suporte pra gente desenvolver atividade na comunidade [...]. Mas como nós não temos suporte só é agente de saúde com o lápis e o papel então a gente não faz [...]" (ACS 09).

Há ainda a formação discursiva que aponta para as práticas que necessitam da utilização da barganha como método de incentivo para que a população vá até o local no qual será realizada a ação educativa, visto que o poder de convencimento para a comunidade está em oferecer algo concreto como prêmios, lanches, exames ou distribuição de algum medicamento para que a população se faça presente, conforme os discursos a seguir:

"[...] sabe o que é que facilita se você promover uma atividade, um evento? Se você colocar que você vai fazer um [...] café da manhã, vai distribuir uma cesta básica está entendendo? Que vai ter um sorteio para poder chamar a atenção isso facilita [...]" (ACS 02).

"[...] a gente fica insistindo, insistindo e eles acomodados. Mas o que eles mais participam é o Hiperdia porque tem o teste da glicemia, aí por esse fator sempre dá mais uma um número de pessoas, porque vai oferecer ali um serviço em si, mas quando é só pra ouvir educação em saúde eles não se interessam [...]" (ACS 04).

“Nós já aprendemos [...] no dia que a enfermeira ou a médica fazem algum exame, este é ó dia para fazer algo, pois é quando eles mais aparecem aqui no posto" (ACS 07).

\section{DISCUSSÃO}

A partir dos discursos dos ACS foi possivel identificar a paráfrase que possui seu conceito interpretado como o que é dito e que está assentado na memória, no estável, no que se repete mesmo que de maneira diferente, no já dizivel, na produtividade, no dizer enrijecido(3), elucidando assim como causa de dificuldade na efetivação da realização das ações de educação em saúde a relutância exposta pela comunidade que alega, em sua maioria, falta de tempo para a participação das atividades coletivas, o que gera baixa adesão e evasão nos atos educativos ofertados pelo ACS.

Entende-se que as dificuldades encontradas pelos ACS para realizar o trabalho educativo, por vezes, estão relacionadas ao desdém da comunidade e falta de tempo, situações estas que impactam negativamente nos atos educativos, bem como pode gerar sofrimento no trabalho do $\mathrm{ACS}^{(5)}$ por não conseguir atuar na promoção da qualidade de vida da população da sua micro área de atuação.

Entende-se que tais resistências postas pela comunidade é em decorrência, em sua maioria, à cultura da medicalização, influenciada pelo modelo biomédico, na qual as ações efetivas de saúde possuem como características a objetividade e a prescrição do tratamento, elementos estes que destoam das ações de prevenção de doenças e promoção da saúde, possibilitadas por meio da educação em saúde.

Assim, faz-se necessário a elaboração de estratégias educacionais que possam viabilizar maior vinculação da comu- 
nidade com as atividades realizadas pelos ACS, bem como a superação do modelo tradicional de assistência à saúde que ainda é presente nesse cenário de atenção e que reverbera na compreensão errônea da comunidade sobre as soluções para os seus problemas de saúde.

Como opção para tal problemática poderia ser as metodologias ativas de ensino, situação na qual a população seria envolvida de forma ativa na construção de novos saberes, motivando a comunidade a atuar como protagonista e, por consequência, rompendo com a educação vertical de receptores de informação e de baixa efetividade.

Neste sentido, compreende-se essas metodologias como importante estratégia para a qualificação do trabalho do ACS, além de possibilitar mais adesão da comunidade nas ações planejadas, já que a mesma estimula a construção de novos saberes de maneira crítico e reflexiva, na qual as pessoas envolvidas, no caso a comunidade, participa e se compromete com o seu aprendizado. As metodologias ativas de ensino propõem a construção de situações que desafiem a capacidade crítica frente à realidade, a reflexão sobre temas que geram dúvidas e hipóteses, a capacidade de criar recursos para pesquisar soluções e suas aplicabilidades ${ }^{(6)}$.

Porém, para a sua aplicabilidade junto às famílias e comunidades, a educação em saúde depende da congruência de diversos fatores, sendo possivel destacar entre eles o incentivo da própria gestão em qualificar os ACS, o que, por vezes, não acontece de acordo com os sentidos dos discursos identificados nesta investigação.

Entende-se que a descontinuidade de auxilio da gestão impacta de forma negativa no trabalho de toda a equipe de saúde ${ }^{(7)}$, porém se faz necessário descortinar a aparente simplicidade que envolve o argumento de transferir somente para a esfera do poder público o motivo para não realização cotidiana da educação em saúde, mas aflorar a esse debate outros elementos, como já abordados por Vasconcelos ${ }^{(8)}$, que são empecilhos para o desenvolvimento dessa prática, como a ancoragem do plano de cuidado em saúde na concepção da patologização do ser humano presente no modelo biomédico, que desvaloriza outras dimensões do cuidar como a própria educação em saúde e foca, preferencialmente, na clínica individual e prescritiva, compreensão esta entendida, por vezes, como boa prática pela própria comunidade, desconsiderando e/ou desvalorizando a educação em saúde como campo de cuidar.

Há ainda como destacar, as relações de poder no cuidado em saúde, já que o mesmo argumenta que nas relações estabelecidas nas microrrelações entre o trabalhador da saúde (ACS) e os usuários, existe a recriação de estruturas de dominação da sociedade, o que acaba, em certas situações, eclipsando o sujeito a ser cuidado em suas reais necessidades de saúde, bem como desconsiderando a voz desses sujeitos, impedindo, assim, a criação de espaços de produção do cuidado mediados pela educação em saúde ${ }^{(8)}$.

Logo, com base nessas discussões, compreende-se que deve haver também a ressignificação da postura do próprio ACS ao reconhecer que o mesmo possui responsabilidade quando não há a realização da educação em saúde, não somente, portanto, culpabilizando terceiros quando essas ações não acontecem.

Por sua vez, quando existem movimentos instituintes ao perceber a educação em saúde como eixo estruturante para transformações da realidade do território adscrito, precedida pela qualificação dos trabalhadores da saúde, valoriza-se e incentiva-se o agir do ACS, como demonstrado em investigações internacionais ${ }^{(9,10)}$. Nesse contexto esses trabalhadores passam a possuir mais reconhecimento e mais satisfação profissional ao conseguir reduzir índices de adoecimento e aumentar o nível de adesão no plano terapêutico, por meio das ações de educação em saúde.

Outro sentido parafrástico que emerge dos discursos dos participantes desta pesquisa é a necessidade que a comunidade tem de que a educação em saúde esteja sempre atrelada a algo concreto ou um serviço oferecido no local da ação, o que caracteriza a utilização da barganha para o comparecimento dos indivíduos nas atividades realizadas, podendo isto ser reflexo do modelo biomédico, no qual o processo de trabalho está vinculado ao adoecimento e procedimentos curativistas centrado na doença como já abordados anteriormente.

Corroborando com os achados de pesquisa que evidencia que ao realizar ações de educação em saúde de forma individual ou coletiva, os profissionais encontram barreiras, na quais pode se identificar a resistência da população em aceitar a mudança ao novo modelo assistencial proposto, já que os usuários ainda reconhecem os serviços da $A B$ como lugar de atendimento individual e de ações curativistas, sendo apontada como alternativa concreta de atendimento das suas necessidades, não percebendo as outras atividades desenvolvidas como estratégias de qualificação e melhoria da saúde (11).

Caracterizando dessa forma desafio para a implementação do novo modelo assistencial na $A B$, no qual o seu alcance depende principalmente do apoio social e no amadurecimento das relações de corresponsabilidade dos profissionais da saúde e sua população adscrita, tornando o processo de transição do modelo biomédico para o atual modelo de assistência dinâmico e multifatorial que sofre influência de inúmeros aspectos. Pois, coexistem elementos dos dois modelos de atenção à saúde que ora no cotidiano possam entrar em conflitos e ora possam se complementar ${ }^{(12)}$. 
Por isso é necessário que ACS tenha boa relação de comunicação com a comunidade e capacitações constantes para dialogar e argumentar os benefícios que a educação em saúde poderá proporcionar, tendo em vista mudança de visão para a população, e assim torná-la mais presentes nessas ações ao fomentar uma relação dialogada e, por consequência, transformações a partir da relação da práxis com a sua realidade ${ }^{(13)}$.

Portanto, o ACS precisa do apoio da sua equipe de saúde e gestão e comunidade para enfrentar as dificuldades que confrontam o seu cotidiano, pois a sua valorização é necessária para o seu crescimento profissional, como também elemento motivador na busca da realização da educação em saúde com vistas ao empoderamento da comunidade do seu território adscrito.

Por fim, acredita-se que mesmo o ACS ainda possuindo um trabalho precarizado, seja pela demanda excessiva ou baixos salários, o mesmo é o pilar para a efetivação das práticas em saúde preconizada pela $A B$, em especial pelo seu perfil de liderança comunitária, já que fazem parte da comunidade em que atuam, característica esta que possibilita a criação de melhor rede de comunicação entre o serviço de saúde e a população sob sua responsabilidade.

\section{Limitações do estudo}

Cabe ressaltar que este estudo apresenta limitações, uma vez que foi desenvolvida com ACS de um municipio, sendo difícil generalizar os resultados para o âmbito nacional, já que os resultados são influenciados pela dinâmica do trabalho de cada trabalhador, comunidade e gestão de sua localidade.

\section{Contribuições do estudo para a prática}

Esta investigação contribui ao demonstrar as dificuldades para a realização da educação em saúde pelos ACS no campo da $A B$ e concomitantemente gerar intelecções sobre caminhos possiveis a serem adotados para amenizar e/ou solucionar tais problemáticas, o que pode gerar boas práticas nesse cenário de atenção e, consequentemente, qualidade de vida da população que usufrui desses espaços de produção do cuidado medida pela educação em saúde.

\section{CONCLUSÃO}

Ao longo do percurso deste estudo buscou-se a partir dos discursos dos ACS analisar as dificuldades experienciadas por esses trabalhadores no seu cotidiano na realização da educação em saúde na $A B$.

Assim, dentre os discursos parafrásticos, os achados durante a discussão permeiam inúmeros fatores que influenciam a realização da educação em saúde, como a pouca valorização da comunidade que não reconhece a importância de se participar de grupos ou atividades coletivas que são planejadas e realizadas pelos ACS, sendo fator que desestimula e frustra o trabalhador da saúde, que por muitas vezes não dá continuidade as atividades em grupo ou individuais.

Outros fatores que contribuem para este cenário é o déficit do apoio da gestão, a ótica que a população tem sobre o cuidado em saúde ainda permanecer atrelado ao modelo biomédico e as relações de poder no campo da $A B$, o que acaba por influenciar os processos cuidativos comunitários, promovendo em sua grande maioria a verticalização das ações de saúde.

Outro ponto observado nesta investigação foi a utilização da barganha para incentivar a participação da comunidade nas ações de saúde o que corrobora para que a educação realizada esteja atrelando ao uso tecnologias duras, como medicamentos e exames, diminuindo o real objetivo da realização das atividades com vista a promoção e prevenção da saúde.

Desta maneira, torna-se importante ressaltar a construção coletiva do cuidado com também buscar opções para superar os empecilhos da rotina de trabalho na qual a atividade em educação em saúde seja vislumbrada não como uma atividade a mais a ser desenvolvida, mas sim como possibilidade de reorientação do modelo de atenção, e por consequência valorização do trabalho do ACS.

Espera-se que os achados deste estudo contribuam para novas discussões e reflexões entre as equipes, comunidades e gestores sobre a importância de se reconhecer as práticas de educação em saúde que o ACS desenvolve no seu cotidiano para o fortalecimento da saúde, da comunidade e do próprio Sistema Único de Saúde (SUS), incentivando a realização de ações educativas ainda que diante das dificuldades, objetivando promover a saúde da comunidade em que trabalha e está inserido.

\section{Contribuição dos autores}

Concepção e desenho, Análise e interpretação dos dados, Redação do artigo, Revisão crítica, Revisão final: Jessica Mayara Almeida Silva; Bruno Dias Batista; Andressa Pereira do Carmo; Marilia Moreira Torres Gadelha e Marcelo Costa Fernandes. 


\section{REFERÊNCIAS}

1. Speroni KS, Fruet IMA, Dalmolin GL, Lima SBS. Percepções dos agentes comunitários de saúde: contribuições para a gestão em saúde. Rev Cuid [Internet]. 2016 [cited 2017 Jan 21]: 7(2): 1325-37. Available from: http://www.scielo.org.co/scielo.php?script=sci_ arttextEpid=\$2216-09732016000200010

2. Teixeira E, Medeiros HP, Garcez J,3 Imbiriba MMBG, Silva BAC Conhecimentos-procedimentos de agentes comunitários de saúde sobre doenças sexualmente transmissiveis: pistas para educação permanente na Amazônia. Enferm Foco [Internet]. 2012 [cited 2018 Fev 12]; 3(2): 71-4. Available from: http://revista.cofen.gov.br/index. php/enfermagem/article/viewFile/258/146

3. Orlandi EP. Análise de Discurso: principios e procedimentos. 11ª ed. Campinas: Pontes Editores; 2013.

4. Brasil. Conselho Nacional de Saúde Brasil [Internet]. Resolução no 466 [cited 2017 Fev 12], de 12 de dezembro de 2012. Brasilia, 2012. Available from: http://bvsms.saude.gov.br/bvs/saudelegis/cns/2013/ res0466_12_12_2012.html

5. Broch D, Souto LHD, Riquinho DL, Dal Pai D. Lives of pleasure and suffering in the work of the community health agent. Ciênc. cuid. saúde. [Internet]. 2018 [cited 2019 Apr 14]; 17(2): 1-7. Available from: http://ojs.uem.br/ojs/index.php/CiencCuidSaude/article/ view/39287/751375137969

6. Pascon DM, Otrenti E, Mira VL. Perception and performance of nursing undergraduates in evaluation of active methodologies. Acta paul. enferm. [Internet]. 2018 Fev [citado 2019 Abr 15]; 31(1): 61-70. Disponivel em: http://www.revenf.bvs.br/scielo.php?script=sci_ arttext\&pid=S0103-2100201800010006l\&lng=pt. http://dx.doi. org/10.1590/1982-0194201800010

7. Soder R, Oliveira IC, Silva LAA, Santos JLG, Peiter CC, Erdmann AL. Desafios da gestão do cuidado na atenção básica: perspectiva da equipe de enfermagem. Enferm Foco [Internet]. 2018 [cited 2018 Apr 12]: 9(3):76-80. Available from: http://revista.cofen.gov.br/index.php/ enfermagem/article/view/1496/465
8. Vasconcelos EM. Educação Popular e a Atenção à Saúde da Familia. 5. ed. São Paulo: Hucitec, 2010

9. Breysse J, Dixon S, Gregory J, Philby M, Jacobs DE, Krieger J. Effect of Weatherization Combined With Community Health Worker In-Home Education on Asthma Control. American J of Public Health [Internet]. 2014 [cited 2018 Mar 12]; 104(1): 54-67. Available from: https://www. ncbi.nlm.nih.gov/pmc/articles/PMC3910032/

10. Maes K, Closser S, Kalofonos I. Listening to Community Health Workers: How Ethnographic Research Can Inform Positive Relationships Among Community Health Workers, Health Institutions, and Communities. American J of Public Health [Internet].. 2014 [cited 2018 Mar 12]; 104(5): 5-9. Available from: https://ajph.aphapublications. org/doi/full/10.2105/AJPH.2014.301907

11. Mendonça FTNF, Santos AS, Buso ALZ, Malaquias BSS. Health education with older adults: action research with primary care professionals. Rev. Bras. Enferm. [Internet]. 2017 Aug [cited 2019 Apr 15]; 70(4): 792-799. Available from: http://www.scielo.br/scielo. php?script=sci_arttextEpid=S0034-71672017000400792\&lng=en. http://dx.doi.org/10.1590/0034-7167-2016-0349

12. Fertonani HP, Pires DEP, Biff D, Scherer MDA. The health care model: concepts and challenges for primary health care in Brazil. Ciênc. saúde coletiva [Internet]. 2015 Jun [cited 2017 Mai 21]; 20(6): 1869-1878. Available from: http://www.scielo.br/scielo.php?script=sci_ arttext\&pid=S1413-81232015000601869\&lng=en

13. Campos KFC, Sena RR, Silva KL. Permanent professional education in healthcare services. Esc. Anna Nery [Internet]. 2017 [cited 2019 Apr 12]; 21(4): e20160317. Available from: http://www.scielo.br/scielo. php?script=sci_arttext\&pid=S1414-81452017000400801\&lng=en. Epub Aug 07, 2017. http://dx.doi.org/10.1590/2177-9465ean-2016-0317 